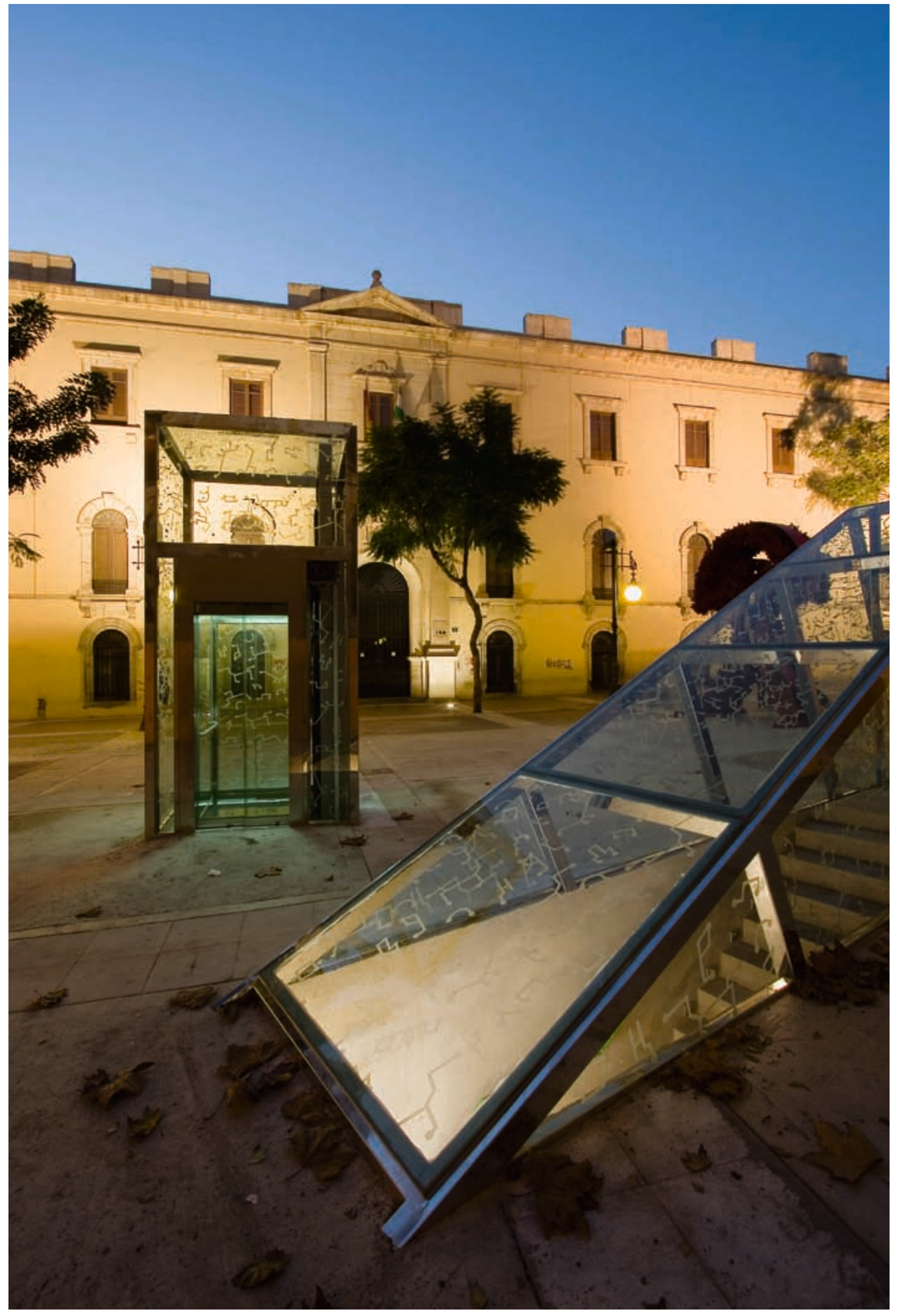




\section{Sobre el respeto y el rigor en la rehabilitación de los refugios}

José Ángel Ferrer, arquitecto

\section{Resumen}

Los refugios de Almería son un conjunto de galerías subterráneas de más de 4500 metros de longitud, construidas durante la Guerra Civil. Sus valores arquitectónico-ingenieril, histórico y cultural, los convierte en uno de los elementos más significativos del patrimonio de la ciudad de Almería. El proyecto se divide en dos partes: la estricta rehabilitación de las galerías donde destaca un pequeño hospital, y la obra nueva en superficie para accesos y salidas.

La idea principal de la intervención en las galerias ha sido garantizar la seguridad de los visitantes sin desvirtuar los espacios originales. En cuanto a las actuaciones en superficie, merece especial mención la localización de los restos de la antigua Puerta de Pechina, de época árabe, bajo el suelo del pabellón de acceso. De esta forma, el edificio aparece como un gran cofre que alberga en su interior dos grandes tesoros, los refugios y los restos de la puerta musulmana. Toda la actuación está plagada de "guiños" al lugar en un intento de vincular el proyecto al contexto físico y cultural, dentro del máximo respeto a lo existente y del más estricto rigor.

\section{Palabras clave}

Almería / Galerias subterráneas / Intervención / Patrimonio inmueble / Puerta de Pechina / Puertas de muralla / Refugios de guerra / Rehabilitación arquitectónica / 1937 
Apenas soy capaz de expresar cuánto me impresionó la primera vez que entré en los refugios. El recuerdo de la soledad y solidez que se respiraba en aquel lugar me ha acompañado a lo largo de todo el proceso de rehabilitación de esta compleja obra, única en su concepción, donde la arquitectura y la ingeniería se dan la mano. Su recuperación como elemento cultural e histórico de indudable interés está estrechamente ligada a su simbolismo como testimonio de la Guerra Civil española. Esta circunstancia, junto a su valor arquitectónico- ingenieril, sitúa a los refugios como una de las obras más importantes, construidas en Almería durante el siglo XX, constituyendo, por tanto, uno de los elementos más significativos de nuestro patrimonio y de nuestra memoria histórica. Definamos a continuación cuáles son sus características principales y el proceso del proyecto que ha culminado con las obras de rehabilitación.

\section{LOS REFUGIOS DURANTE LA GUERRA}

Los refugios de Almería son un conjunto de galerías y espacios subterráneos, de 4,5 km de longitud, construidos entre 1937 y 1939 según proyecto del arquitecto Guillermo Langle. Su objetivo era proteger de los bombardeos a los casi 40000 habitantes de la ciudad de Almería durante la guerra.

\section{Los accesos}

La entrada a los refugios se realizaba a través de dos tipos de accesos: unos públicos y otros privados. Los primeros se situaban en las aceras y mediante escaleras descubiertas de 1,30 metros de ancho, descendian sin descanso hasta las galerias. Los privados se encontraban a nivel de las propias galerias subterráneas y partían de viviendas particulares o edificios públicos. Entre estos últimos, merecen destacarse los que se producian desde las distintas parroquias de la ciudad. Algunas de ellas disponian incluso de sus propios refugios a través de los cuales se accedía a los de la red general. Tal es el caso de la iglesia de San Pedro, cuyos refugios situados bajo la nave principal podian albergar a más de doscientas personas.

Según los planos originales, se construyeron 101 accesos públicos dispuestos de forma que desde cualquier punto habitado de la ciudad se pudiera localizar una boca de entrada a menos de cien metros. El número de accesos privados es difícil cuantificar, al encontrarse muchos de ellos completamente tapiados y no disponer de planimetría alguna que refleje su situación. No obstante, según testimonios de la época, se sabe que se concentraban en las galerias del paseo y alrededores, por lo que estimamos que rondarían la veintena.

Una vez finalizada la guerra, algunos accesos se utilizaron como aseos públicos hasta los años setenta, otros se tapiaron y cegaron completamente. El resto se cubrieron con unos pequeños kioscos proyectados por Guillermo Langle, en un exquisito ejercicio, más expresionista que racionalista, y de los que apenas han llegado ejemplos originales hasta nuestros dias. Su demolición o las múltiples reformas que sufrieron desvirtuaron completamente el volumen y diseño original. En los últimos años, sólo se han mantenido fieles al proyecto inicial algunos kioscos como los situados en las plazas Urrutia y Marqués de Heredia, esta última muy próxima a la actual salida de los refugios.

\section{Las galerías}

Las galerías se construyeron entre ocho y doce metros de profundidad coincidiendo, generalmente, con los ejes de las calles. La altura libre a la que tienden todas es de 2,20 metros que es la estrictamente necesaria para que, una vez colocadas las luminarias, pueda pasar cómodamente una persona completamente erguida. Sin embargo, las dificultades del terreno y la presencia ocasional del nivel freático hicieron que en algunos puntos esta altura se viera reducida hasta 1,80 metros, tal y como sucede bajo la calle General Tamayo.

El ancho de las galerías está directamente relacionado con el uso al que se destinaron, estableciéndose tres grandes categorias: las galerías-refugio, de 1,50 a 2,00 metros, que constituyen propiamente los refugios y que disponen de bancos corridos en uno o ambos lados dependiendo de su anchura; las galerias de conexión, de 0,90 a 1,50 metros, cuya función principal era conectar los diferentes refugios entre ellos, permitiendo asi una mayor fluidez en las comunicaciones subterráneas que facilitaría la rápida evacuación durante situaciones de bloqueo de alguno de los accesos. Por último, las galerías de ventilación a las que nos referiremos más adelante.

\section{La galería del Paseo}

El mayor tramo recto de galería (545,42 × 2 metros) es el que se desarrolla bajo el Paseo de Almería que, después de su ejecución en 1937, se conectaría con el Refugio existente en la Plaza Virgen del Mar mediante una galería de un metro de ancho por dos de alto. Los dos metros de ancho del tramo del Paseo permiten la existencia de bancos corridos a ambos lados. Además, este tramo dispone de una serie de espacios anexos, que prestaron un servicio vital durante la guerra a las personas que los utilizaron. Entre estos espacios, aparece como elemento más significativo un pequeño hospital compuesto por quirófano, sala anexa con 8 literas, botiquín con lavabo y sala de espera para 20 personas. También se debe hacer mención a un espacio situado a una cota más profunda que el resto de las galerias, por debajo de los doce metros bajo la cota de la calle, que hemos denominado área de uso reservado, donde aparecen 12 literas de obra y 4 hornacinas en los laterales, cuyo destino pudo ser el almacenaje de todo tipo de productos, desde alimentos hasta armamento o incluso como área de descanso o uso reservado.

\section{La construcción}

La ejecución de las galerias se realizó en hormigón ciclópeo, mediante bóvedas de cañón rebajadas, apoyadas sobre muros de espe- 
sor variable entre 40 y $60 \mathrm{~cm}$. De los análisis realizados se han obtenido resistencias de los hormigones de hasta $25,20 \mathrm{~N} / \mathrm{mm}^{2}$, valor superior al exigido actualmente para los edificios de viviendas.

El acabado de las galerías se ejecutó con cal: blanca en las bóvedas, dejando ver las marcas del encofrado y coloreada en las paredes sobre una capa de mortero de revestimiento. El pavimento lo constituye la propia capa superior de una solera de hormigón en masa de quince centímetros de espesor.

Mención especial merece el área del hospital. La zona de espera presenta pavimento de mármol de Macael alternando piezas blancas y grises. Las paredes se encuentran revestidas con estucos grabados y los bancos con baldosas hidráulicas de dibujos geométricos. La sala de operaciones está pavimentada con mármol blanco Macael y los paramentos se acabaron con azulejos de color azul cobalto, que se han mantenido prácticamente intactos hasta nuestros días.

\section{La seguridad}

La seguridad de los refugios estaba garantizada mediante la solidez de sus elementos constructivos y por las diferentes instalaciones que disponian: iluminación eléctrica, ventilación y protección contra las ondas expansivas y avalanchas. Veamos en qué consistían estas últimas de forma más pormenorizada.

La instalación eléctrica alimentaba una red de bombillas incandescentes situadas cada $5 \mathrm{~m}$ a lo largo de la clave de la bóveda. La ventilación se resolvía mediante tubos de fibrocemento de 200 $\mathrm{mm}$ de diámetro, que arrancaban desde el extremo de pequeñas galerías de ventilación de 5 a 10 metros de longitud y un metro de ancho, construidas perpendicularmente a los tramos principales. La situación de los tubos de ventilación, alejados de las zonas donde se encontraban las personas, reducia el riesgo de accidentes en el caso de que cayeran granadas u otros artefactos a través de las bocas exteriores que asomaban por la superficie. Los tubos Ilegaban a alcanzar más de 15 metros de altura al tener que atravesar la importante capa de terreno que cubre las galerías. Los restos de uno de los tubos de ventilación originales se pueden observar, en la calle General Tamayo, adosados a la fachada sur del edificio del Teatro Cervantes. En ocasiones, los tubos exteriores se sustituian por bancos que incorporaban orificios para ventilación, quedando integrados dentro del mobiliario urbano.

Para evitar la propagación de las ondas expansivas dentro de las galerias, se levantaron elementos de hormigón de un metro de espesor a modo de contrafuertes, coincidiendo con los accesos y situados al tresbolillo. Además, la situación de estos obstáculos contribuía a que la entrada de las personas se realizara de una forma más ordenada disminuyendo así el número de accidentes como consecuencia de las avalanchas. En cualquier caso, las situaciones de estrés inducidas por el sonido de las sirenas situadas en la zona de Oliveros avisando sobre la presencia de

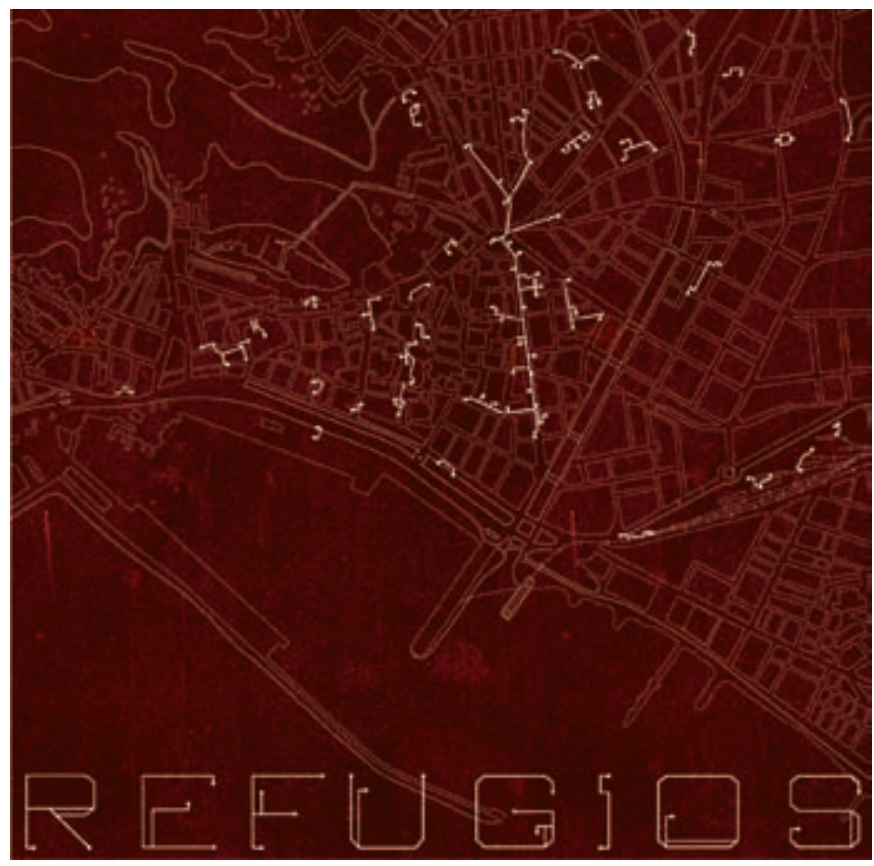

Panel de la entrada del Pabellón de acceso a los refugios. Foto: Jesús Granada
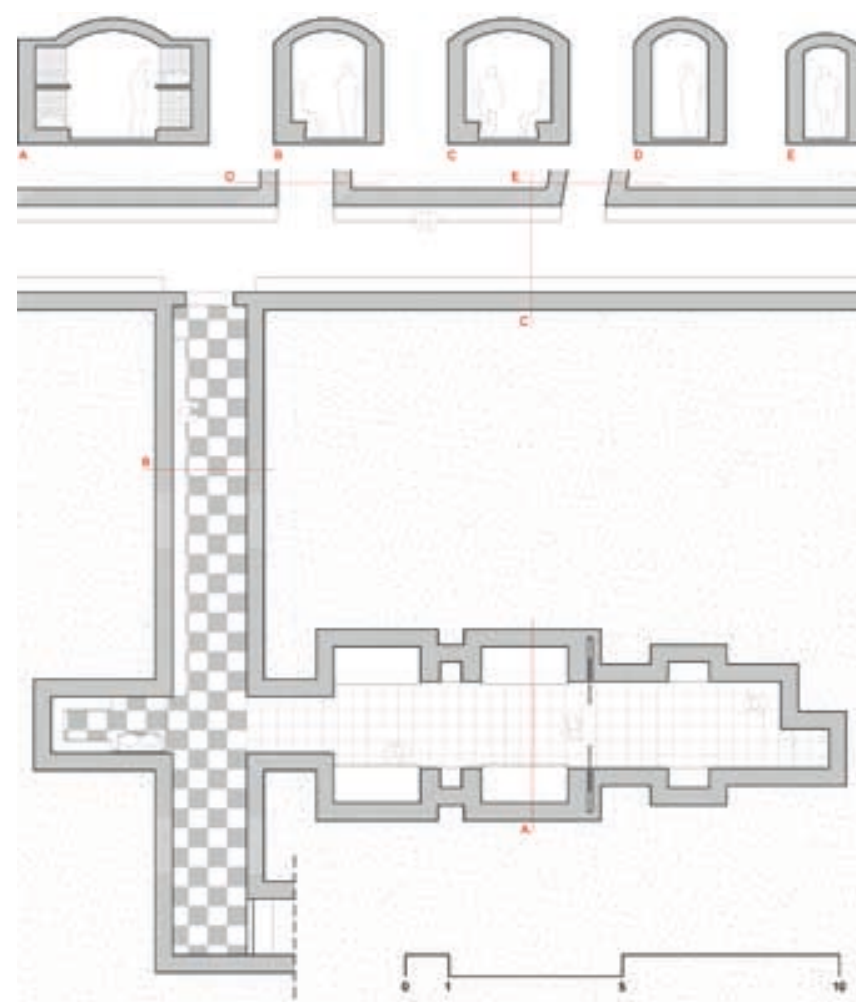

Planta de la zona del quirófano. Fuente: Ferrer Arquitectos

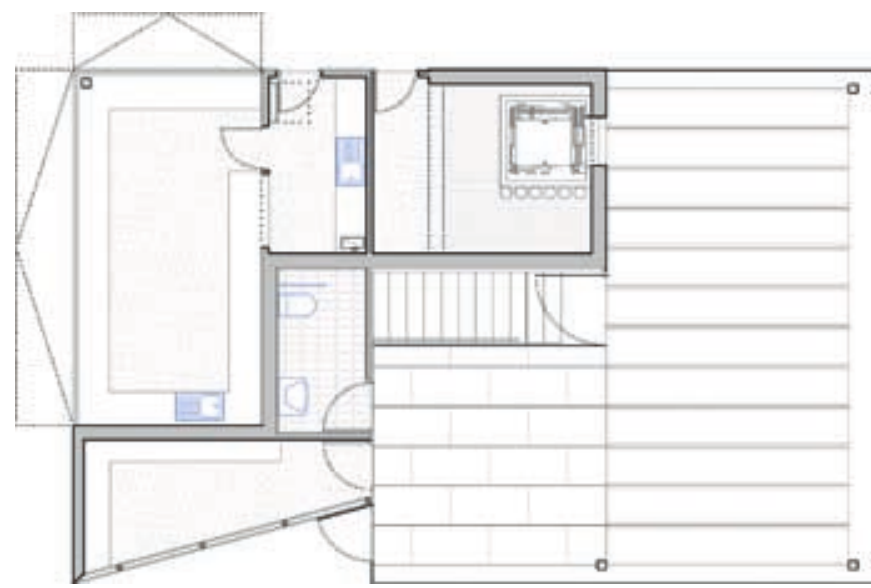

Pabellón de acceso. Fuente: Ferrer Arquitectos 


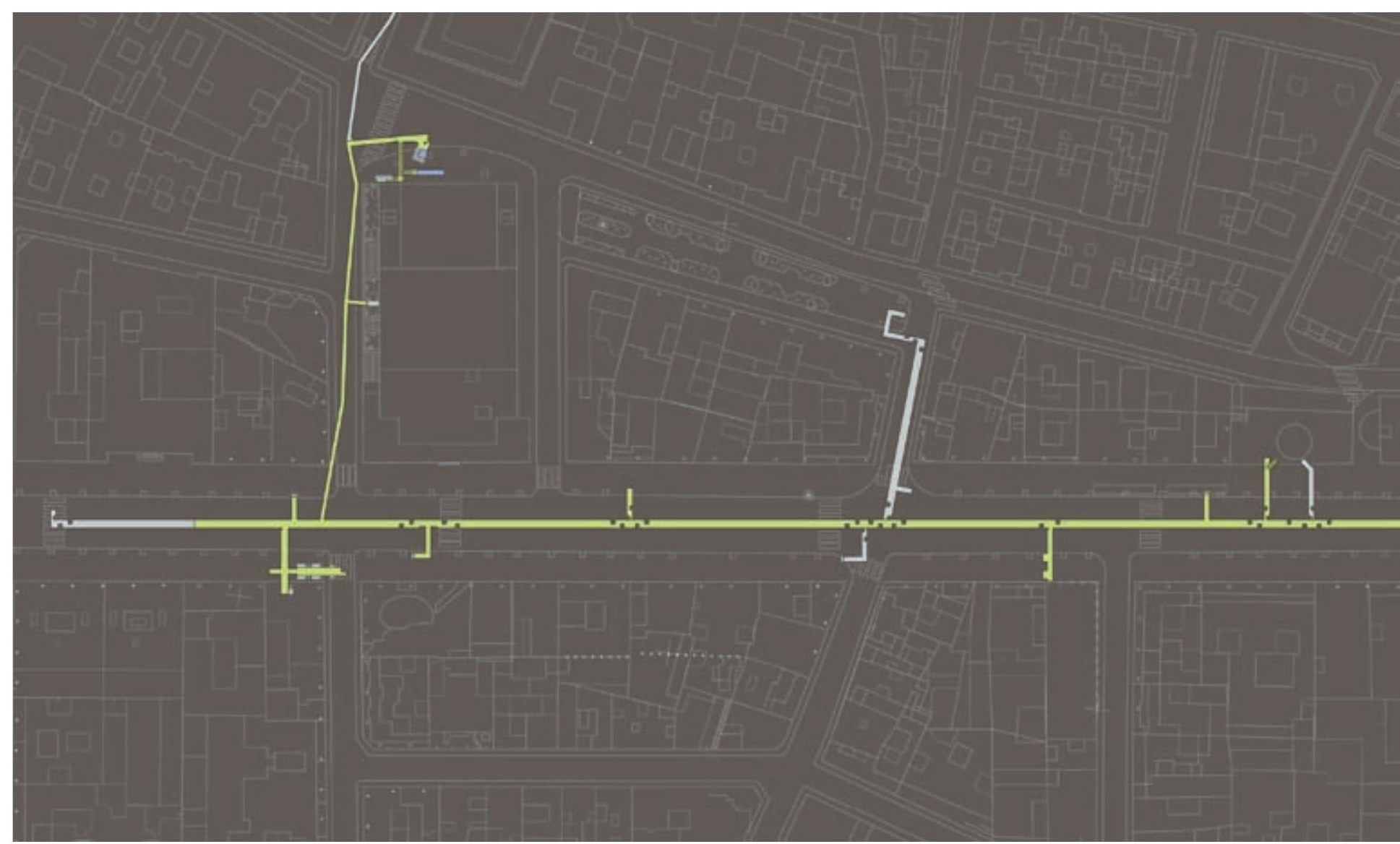

Tramo visitable de los refugios de Almería. Fuente: Ferrer Arquitectos

peligro inminente provocaban aglomeraciones en las entradas que originaban todo tipo de incidentes. Algunos testimonios de la época relatan cómo había personas que, presas del pánico, se lanzaban prácticamente de cabeza a los refugios, aprovechando el colchón humano que se agolpaba en las entradas.

\section{EL VALOR AROUITECTÓNICO DE LOS REFUGIOS}

Aunque nadie pone en duda el evidente valor histórico de los refugios al tratarse de un testimonio esencial para el estudio y análisis de la Guerra Civil española, resulta menos tangible y aparente su valor arquitectónico. Sin embargo, el origen de los refugios, cuyo objeto fundamental era salvar vidas humanas, los hace acreedores de la máxima expresión de lo que, según muchos autores, supone la esencia de la arquitectura: un refugio para la vida.

El refugio subterráneo como ámbito o espacio que el hombre ha utilizado tradicionalmente para protegerse está presente a lo largo de la vasta historia de la arquitectura en numerosos y diferentes momentos. Quizás uno de los más conocidos sea en época del Imperio Romano coincidiendo con la construcción de las catacumbas. Aunque existe la creencia de que los cristianos de Roma crearon las catacumbas para protegerse de las persecuciones que tuvieron lugar en el siglo III, estudios recientes han demostrado que no fue asi y que sólo se trataba de cementerios subterráneos que permitian a los cristianos dotarse de sepulturas dignas, aunque eventualmente sirvieran para protegerse de las persecuciones. En cualquier caso, podemos hablar de un refugio pos mortis, ante la imposibilidad de enterramientos en superficie. Otros ejemplos de construcciones bajo tierra los encontramos en la región de Capadocia en Turquía, donde se localizan construcciones subterráneas habitadas desde hace siglos y que han mantenido su uso hasta nuestros dias; en el desierto del Sahara, donde este tipo de construcciones se remontan a los primeros pobladores o en un entorno más próximo, en las casas subterráneas de Villacañas en Toledo, de gran interés etnográfico.

Existen también otros refugios cuyo origen es similar a los de Almeria, aunque solo han llegado a nuestros dias pequeños tramos de escasa superficie: en Europa los más relevantes son los de Berlin y Londres, que se construyeron durante la Segunda Guerra Mundial. En España, coincidiendo con la Guerra Civil, algunas ciudades, además de Almería, también acometieron la construcción de refugios subterráneos. Algunos de los ejemplos más conocidos son los de Barcelona o Cartagena.

En todos los casos expuestos, los refugios se plantean como galerías subterráneas que permiten el acceso a un espacio más amplio donde se alojaron sus usuarios. Pero los refugios de Almería difieren en algunos aspectos de los anteriores:

En primer lugar, se conservan prácticamente en su totalidad apareciendo como una auténtica ciudad subterránea de supervivencia bajo la ciudad aérea de superficie. Están interconecta- 


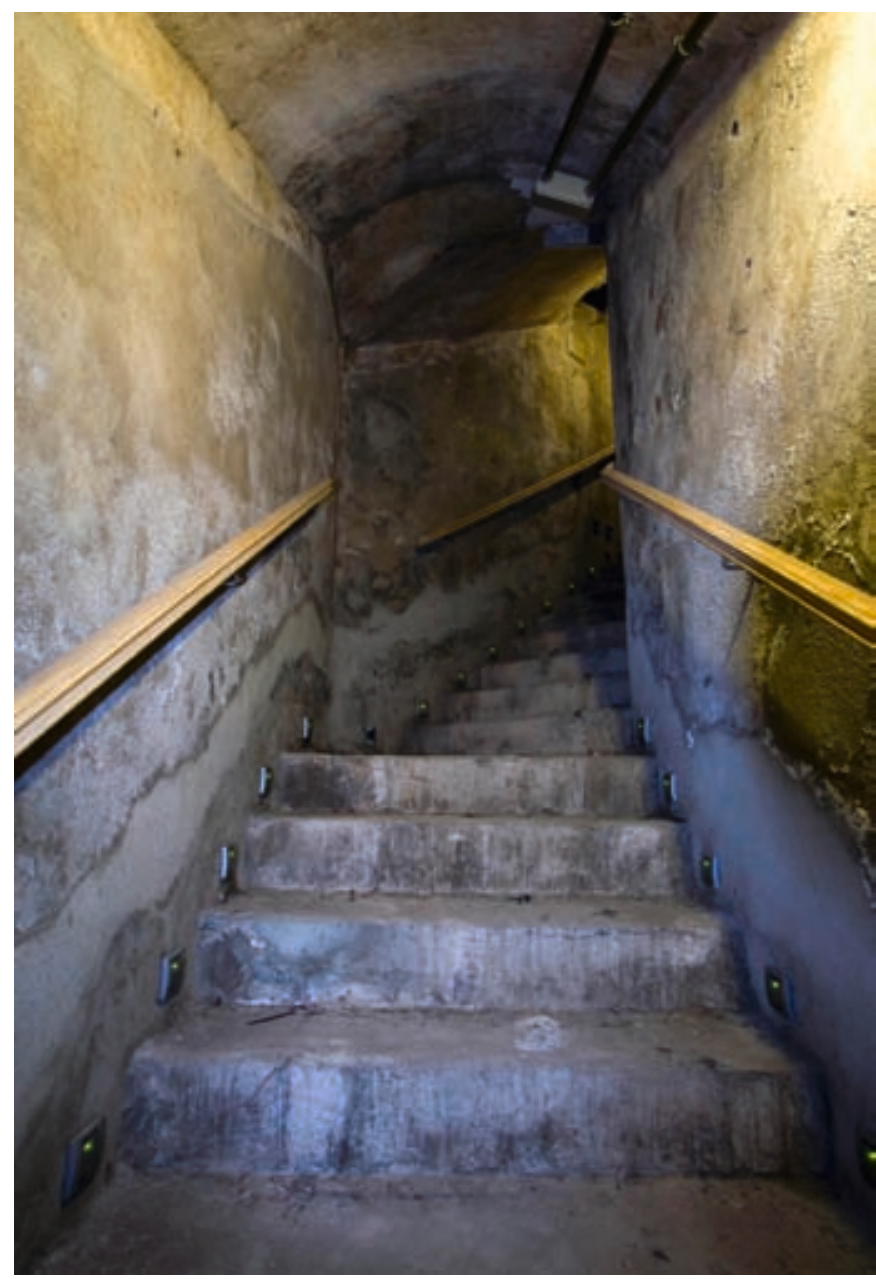

Escalera de salida. Foto: Jesús Granada

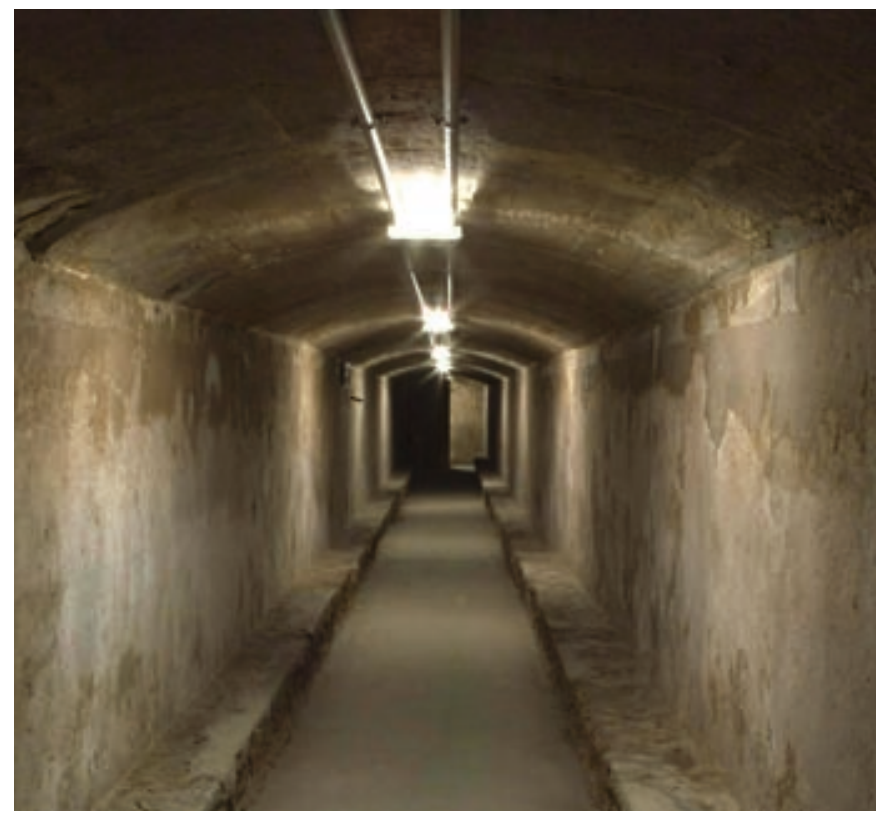

Refugio bajo el Paseo de Almería. Foto: Jesús Granada

La constancia y el rigor que subyace en todos los trabajos acometidos han dotado a los refugios de la afinación necesaria para que volvamos a escuchar su sonido original los refugios, que aumentan, aún más si cabe, su interés y expectación. La continuación de los trabajos tendentes a desvelar algunas de las incógnitas que subyacen en toda la actuación deberá contribuir, entre otros aspectos, al afianzamiento de su indudable valor arquitectónico.

\section{LA REHABILITACIÓN DE LOS REFUGIOS}

En una de las ocasiones en las que Rafael Moneo escribió sobre la ampliación del Museo del Prado afirmó que: "La aceptación rigurosa de los límites no debe suponer menoscabo de la libertad". Esta aserción inspirada en la que Paul Valéry manifestara en su Eupalinos: "La mayor libertad nace del mayor rigor (la plus grande liberté naît de la plus grande rigueur)" da muestra de la dificultad que encierra el proyecto arquitectónico al intervenir sobre espacios ya consolidados de la ciudad y con una importante carga histórica. Es por ello, por lo que rescatamos estas palabras del arquitecto navarro, en el convencimiento de que su espiritu ha impregnado todo el proceso de gestación del proyecto de rehabilitación de los refugios antibombardeos de Almería.

Preservar nuestro patrimonio implica, en ocasiones, intervenir con nuevos elementos que permitan dotar a lo preexistente de las infraestructuras mínimas necesarias para su mantenimiento y puesta en uso. Todo ello debe ir acompañado de la imprescindible reflexión y análisis del entorno que nos permita establecer los vínculos y relaciones del proyecto con el lugar. Este principio, que se ha mantenido vigente en todo el proceso de actuación en los refugios, permitirá el entendimiento de la intervención realizada en relación con su contexto físico y cultural. Vamos a describir a continuación cómo ha sido el proceso que ha culminado con la obra rehabilitada.

El proyecto afecta fundamentalmente al tramo que discurre bajo el Paseo de Almería. De los 4500 metros existentes en la ciudad se han recuperado 965,18 metros de los cuales sólo 756,30 son visitables, el resto se han destinado a instalaciones y recorridos de emergencia. La rehabilitación debía dotar a los refugios de todos los servicios necesarios para su uso público como un elemento más del patrimonio histórico de la ciudad de Almería.

Nuestro primer contacto con esta apasionante obra se produjo a principios de 2005 como consecuencia de la adjudicación del proyecto, que desde las bases del concurso ya nos provocó un enorme interés. Poco a poco, como si de un tesoro muy valioso se tratara, fuimos desvelando muchas de las incógnitas que se cernían sobre los refugios: desde el descubrimiento de galerias y accesos que no se reflejaban en los planos originales hasta el establecimiento de las pautas lógicas de funcionamiento de cada uno de los espacios que iban apareciendo.

Uno de los objetivos de las obras de rehabilitación ha sido que la arquitectura de los refugios vuelva a vibrar como instrumento 


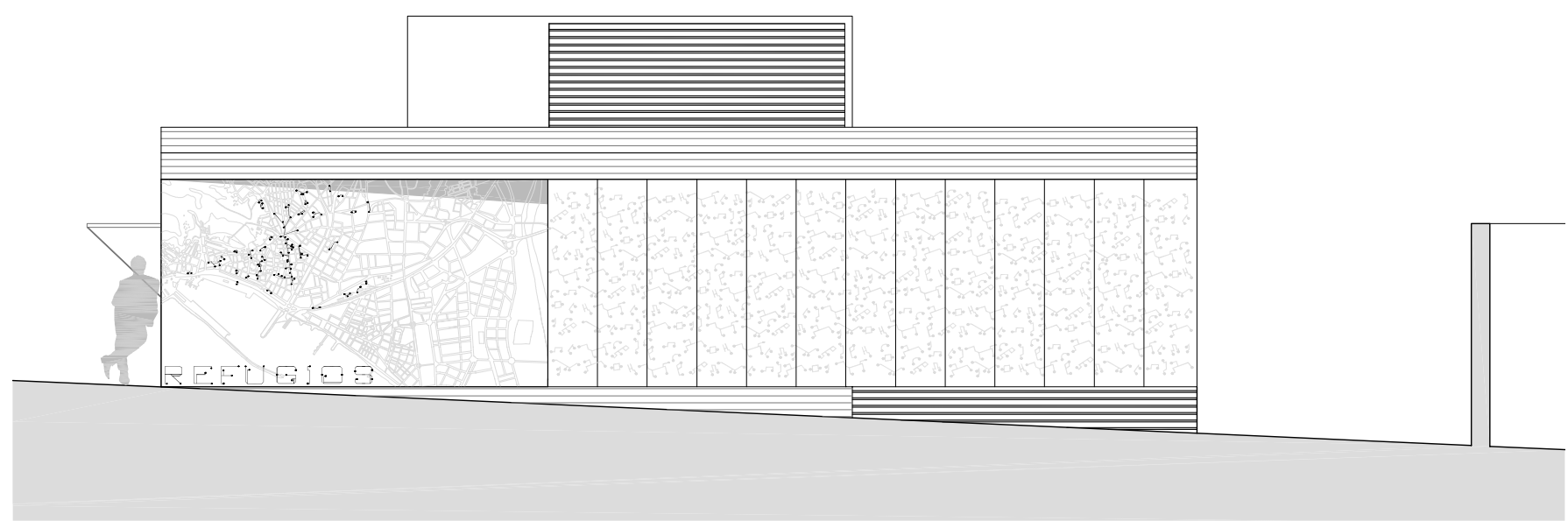

Pabellón de acceso. Alzado norte. Fuente: Ferrer Arquitectos
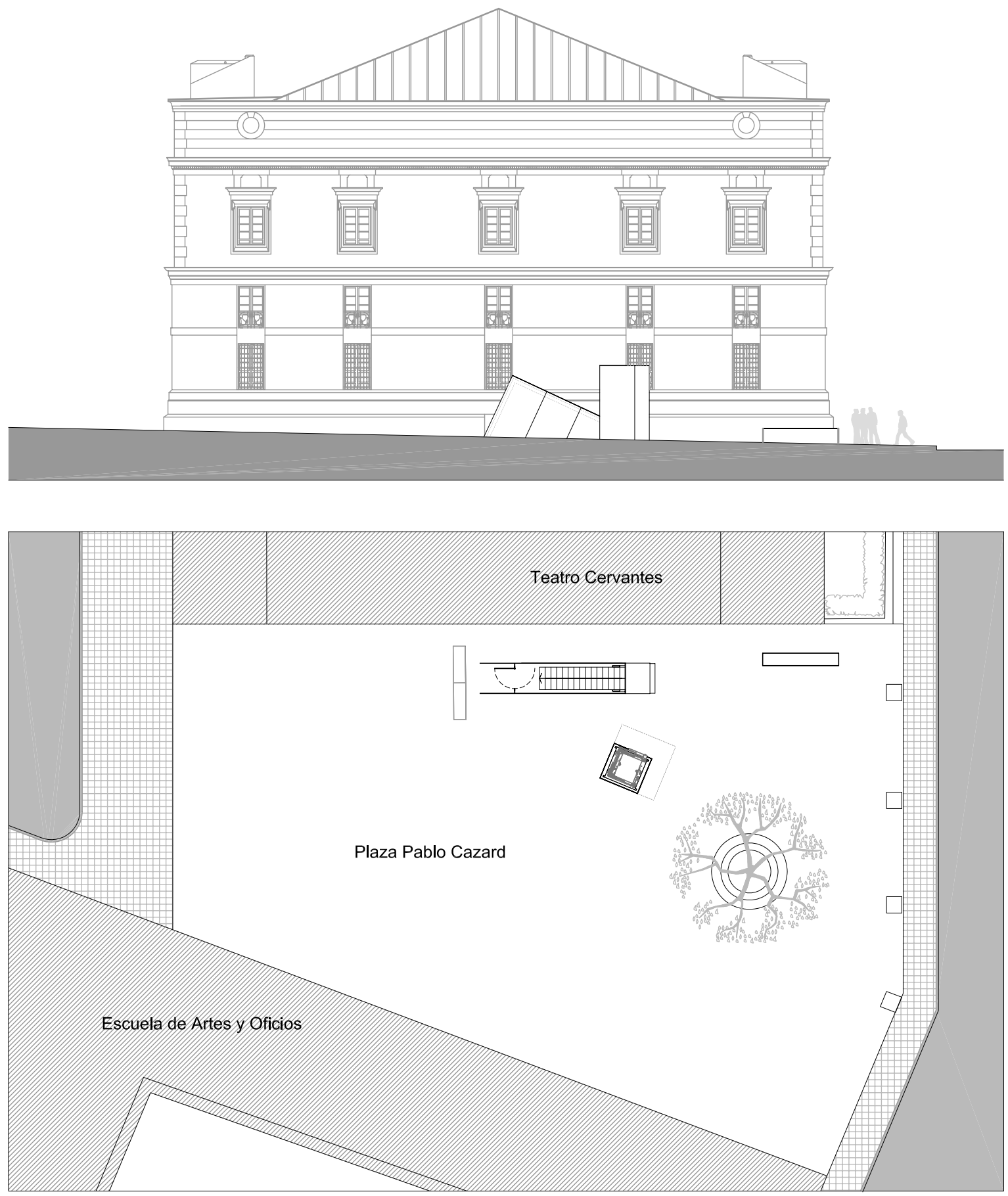

Relación en alzado con el Teatro Cervantes y planta del conjunto de salida. Fuente: Ferrer Arquitectos 
desempolvado después de un largo letargo. Creemos modestamente que la constancia y el rigor que subyace en todos los trabajos acometidos han dotado a los refugios de la afinación necesaria para que volvamos a escuchar su sonido original.

Cuando nos enfrentamos al proyecto de rehabilitación, nos encontramos con dos cuestiones que condicionarian sobremanera su resultado final: por una parte, la rehabilitación de las galerias debía garantizar la seguridad de los visitantes, atendiendo a los requerimientos de las normativas actuales, pero sin desvirtuar los espacios originales; por otra parte, debíamos plantear unos accesos que permitieran el control del alto número de visitas previstas y que entendiamos debian coincidir con los accesos originales, que se encontraban en unos espacios libres ya consolidados en la ciudad y además dentro de unos entornos con un acusado valor histórico. Merece especial mención la presencia de los restos de la antigua Puerta de Purchena en el lugar previsto para el acceso principal.

Estos restos de gran valor arqueológico y de enorme importancia para el conocimiento de nuestro pasado los hemos tenido muy presentes a lo largo de todo el proyecto.

Antes de continuar con el proceso de gestación del proyecto encaminado a la resolución de ambas cuestiones, quisiéramos subrayar la importancia que tiene proseguir con los trabajos arqueológicos encaminados a la recuperación de los restos mencionados. Sería necesario completar los trabajos ya iniciados, con objeto de que quedara de manifiesto todo el ámbito de la antigua Puerta de Purchena, que incluia un recinto interior anexo a la muralla que provocaba la entrada en recodo a la ciudad intramuros. Esta actuación contribuiría al mejor entendimiento y comprensión de la que otrora fuese la entrada principal a la ciudad de Almeria.

\section{La rehabilitación de las galerías}

El proyecto de rehabilitación de los refugios debia ser lo más respetuoso posible con los espacios originales de las galerias. Como ya hemos anticipado, los estrictos requerimientos de las normativas actuales debian adaptarse en lo posible a lo existente y todo ello sin menoscabo de la seguridad de los visitantes. La singularidad de los refugios de Almería nos obligaba a buscar soluciones alternativas a las habituales, cuyo impacto sobre lo existente fuese mínimo y el respeto sobre lo construido máximo. Así, la intervención evitaría que los refugios se convirtieran en un proyecto más, donde los elementos de las instalaciones restaran protagonismo a los evocadores espacios originales, auténticos leit motiv de esta singular obra. Este principio lo hemos mantenido hasta el final, aunque no sin dificultad.

El estado de las galerías era muy desigual. Nos encontramos con tramos que se conservaban en condiciones aceptables y otros donde los vertidos incontrolados de algunos edificios próximos, junto con la erosión provocada por las raices de los árboles y la falta de ventilación, estaban deteriorando a ritmo lento pero constante los elementos constructivos, aunque todavía sin llegar a afectar a su seguridad estructural. Teniendo en cuenta lo anterior, se ha procedido a la consolidación de las galerías y se han reforzado exclusivamente aquellos elementos que se encontraban más deteriorados.

Los nuevos sistemas de ventilación se han ejecutado sobre las conducciones previstas en el proyecto original, aunque aumentando su rendimiento con la incorporación de elementos mecánicos de extracción e impulsión.

El complejo sistema de instalaciones se ha ocultado bajo la solera de la galería, apareciendo sólo en la bóveda dos tubos de acero que hacen referencia a los dos hilos de cobre que alimentaban la iluminación original, que estaba formada por aisladores cerámicos blancos y bombillas incandescentes protegidas por rejillas metálicas.

El sistema de protección contra incendios se ha proyectado teniendo en cuenta que la galería principal mantiene una carga al fuego prácticamente nula. Los elementos susceptibles de combustión se han situado en las galerias de ventilación que disponen de un sistema autónomo e independiente para la extracción de humos, evitando asi su propagación hacia la galería principal en caso de incendio.

En el quirófano se ha realizado un trabajo de cirugía en la limpieza y conservación de todos sus elementos, manteniendo los azulejos originales y protegiendo los estucos grabados de la sala de espera. Se ha prescindido de la reposición de piezas mediante copias actuales, en el convencimiento de que lo existente era suficiente para reflejar el carácter original de la obra.

En definitiva, la imagen final de las galerias se mantiene fiel a sus orígenes, aunque dotada de todos los elementos necesarios para preservar la seguridad de los visitantes.

\section{La entrada y la salida}

Originalmente, los refugios disponian de diferentes y numerosos accesos, que se utilizaban indistintamente como entradas o salidas, facilitando asi la rápida protección de la población. La puesta en valor de los refugios como elemento que forma parte del patrimonio histórico de la ciudad, casi setenta años después de su ejecución, ha requerido de nuevas consideraciones en cuanto a la forma de recorrerlos, independizando la entrada de la salida. Las dos se han situado en espacios donde ya existían accesos originalmente: Ia plaza Manuel Pérez García y la plaza Pablo Cazard.

La adopción de formas compactas y transparentes de geometría pura y elemental se realiza en el convencimiento de que son las más adecuadas para la integración de un elemento arquitectónico en unos entornos históricos como el de la antigua Puerta de Purchena y el de la Escuela de Artes, donde lo histórico y preexistente deben prevalecer sobre cualquier otra actuación, pero sin negar 


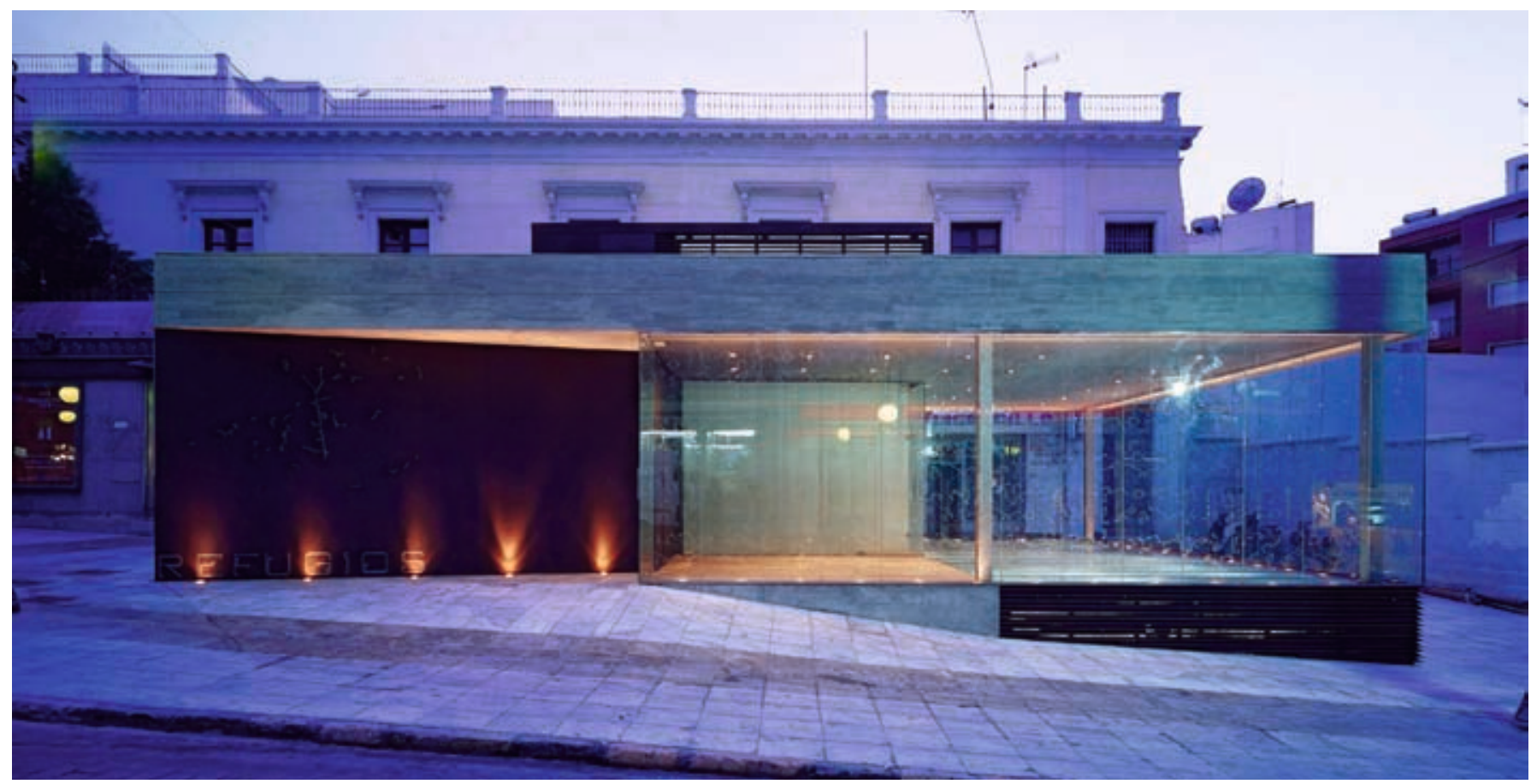

Entrada al Pabellón de acceso a los refugios. Foto: Jesús Granada

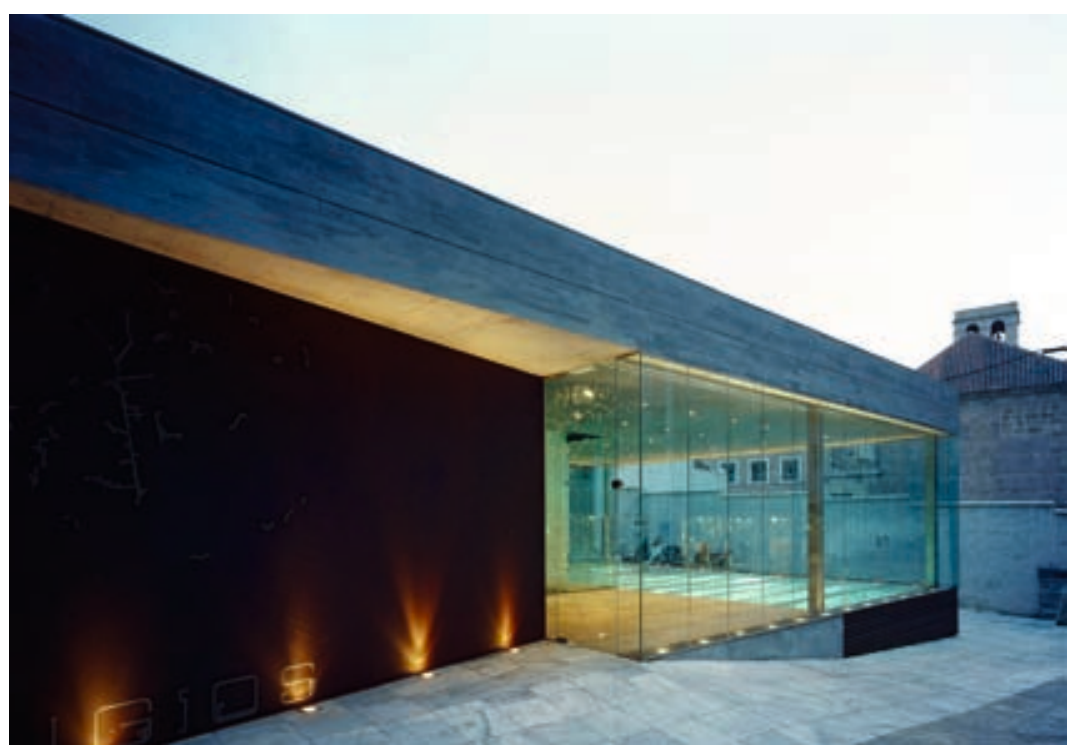

Entrada al Pabellón de acceso. Foto: Jesús Granada

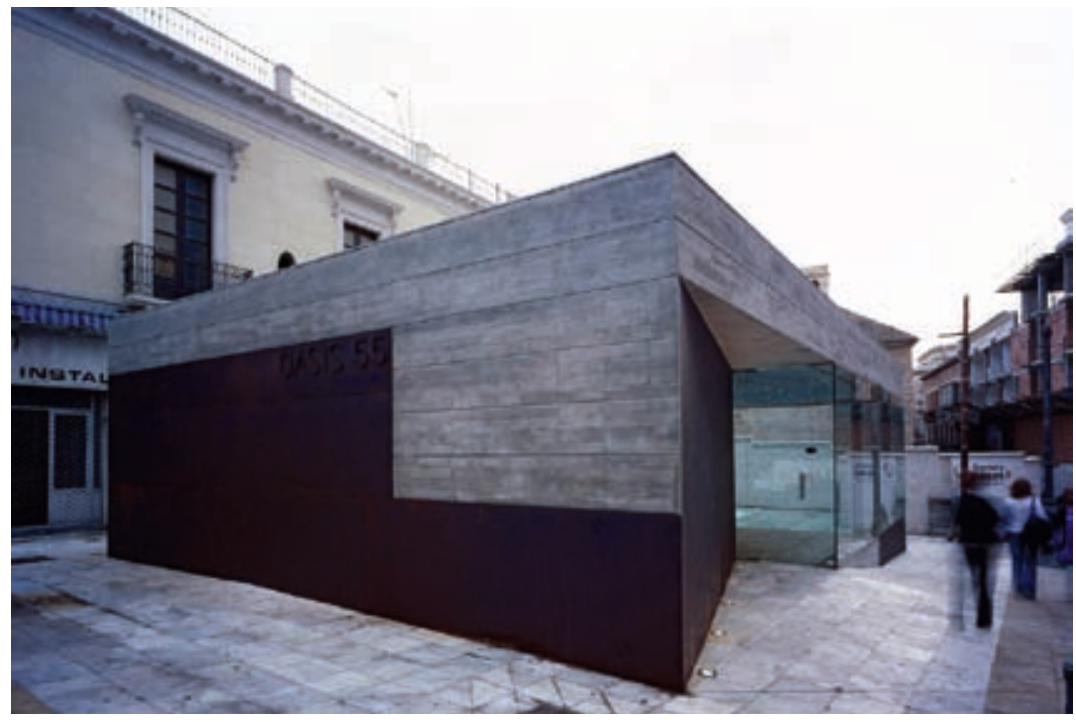

Vista nordeste del Pabellón de acceso. Foto: Jesús Granada

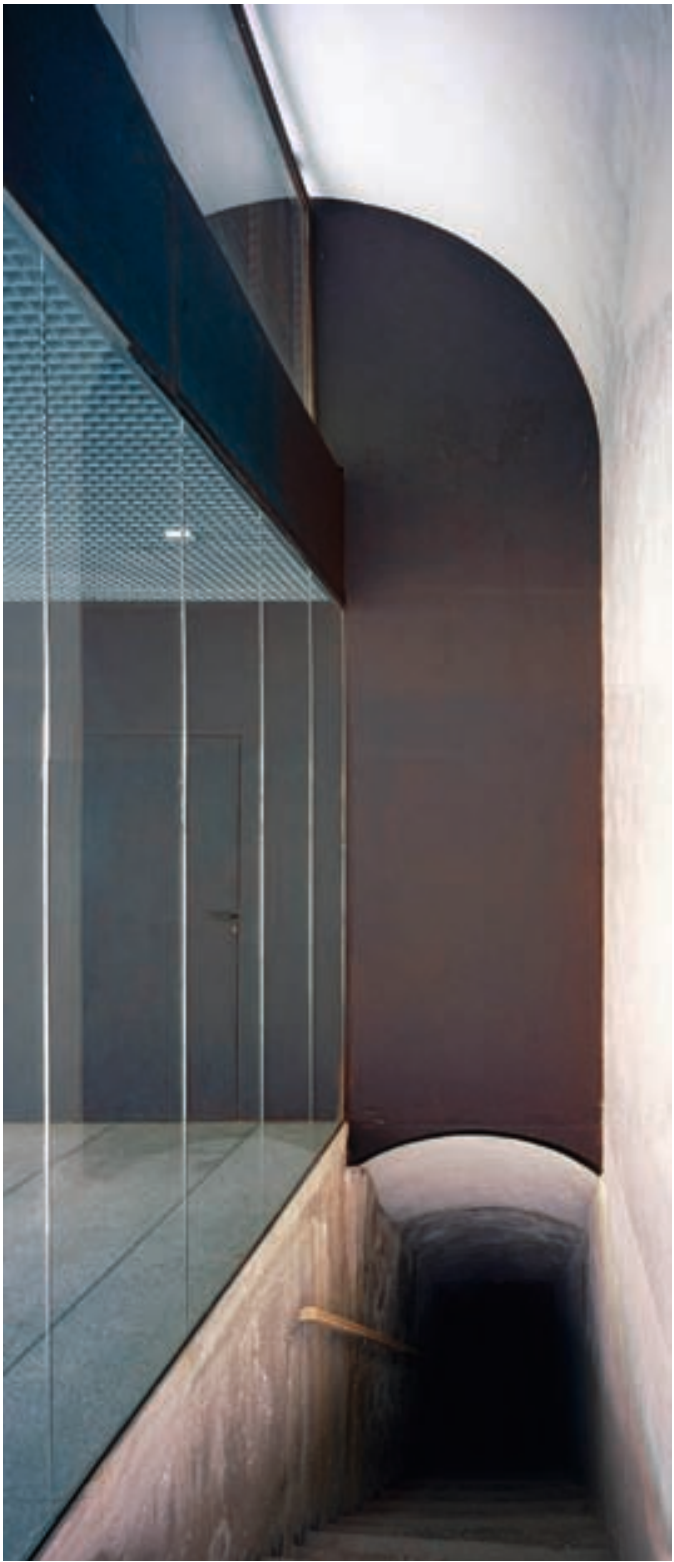

Acceso a refugios y lucernario en Pabellón de entrada. Foto: Jesús Granada 


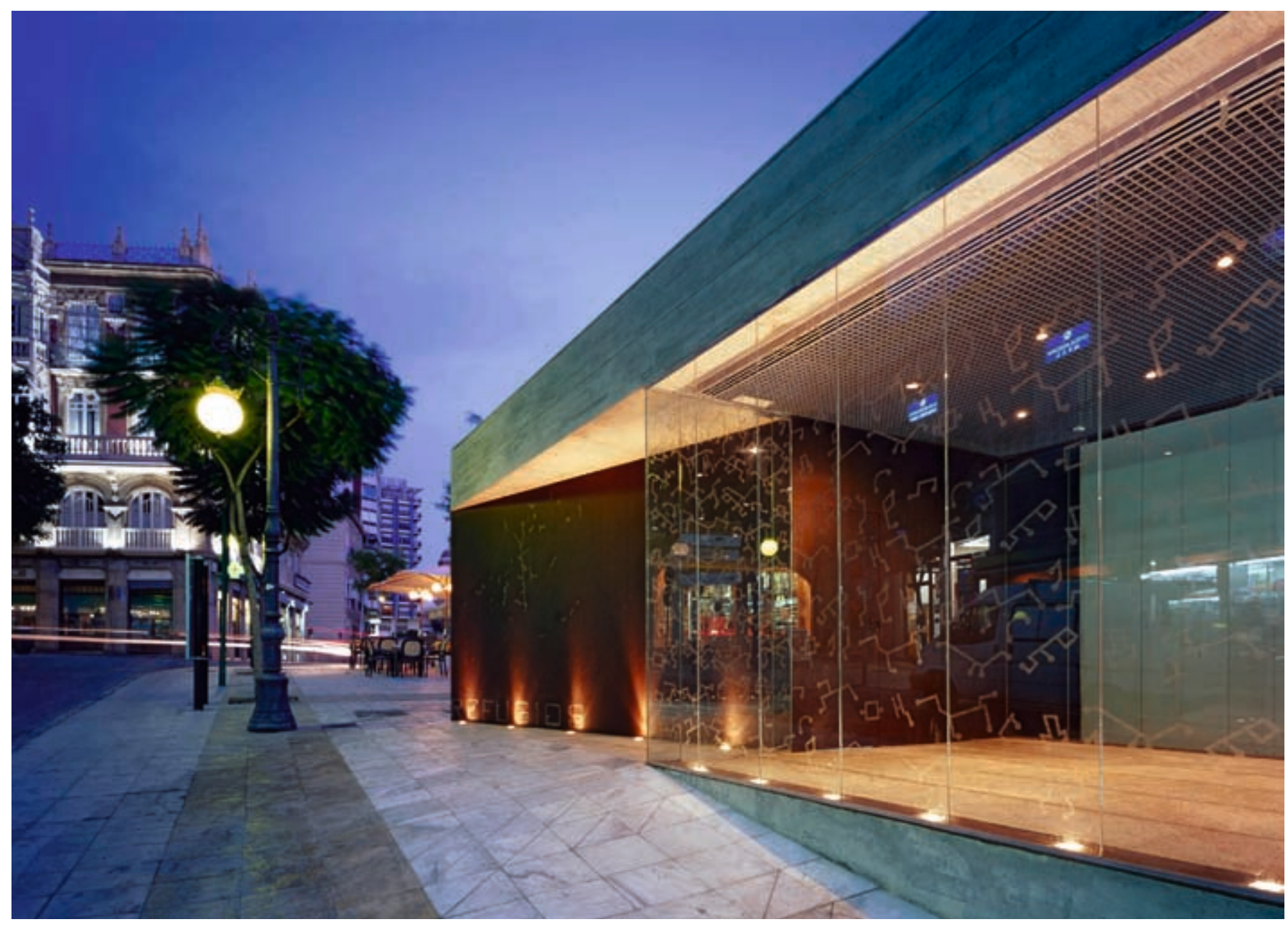

Entrada al Pabellón de acceso a los refugios. Foto: Jesús Granada

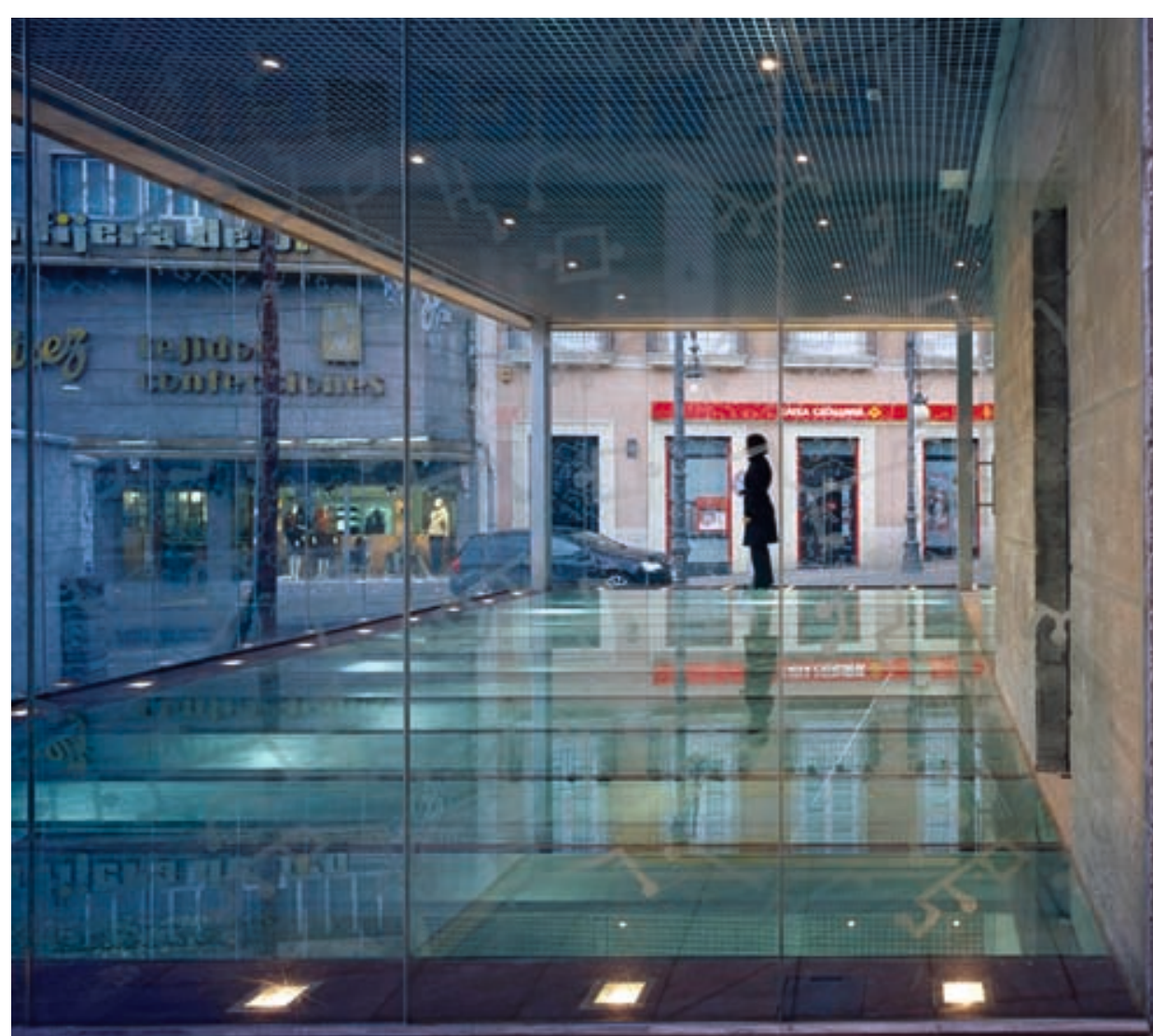




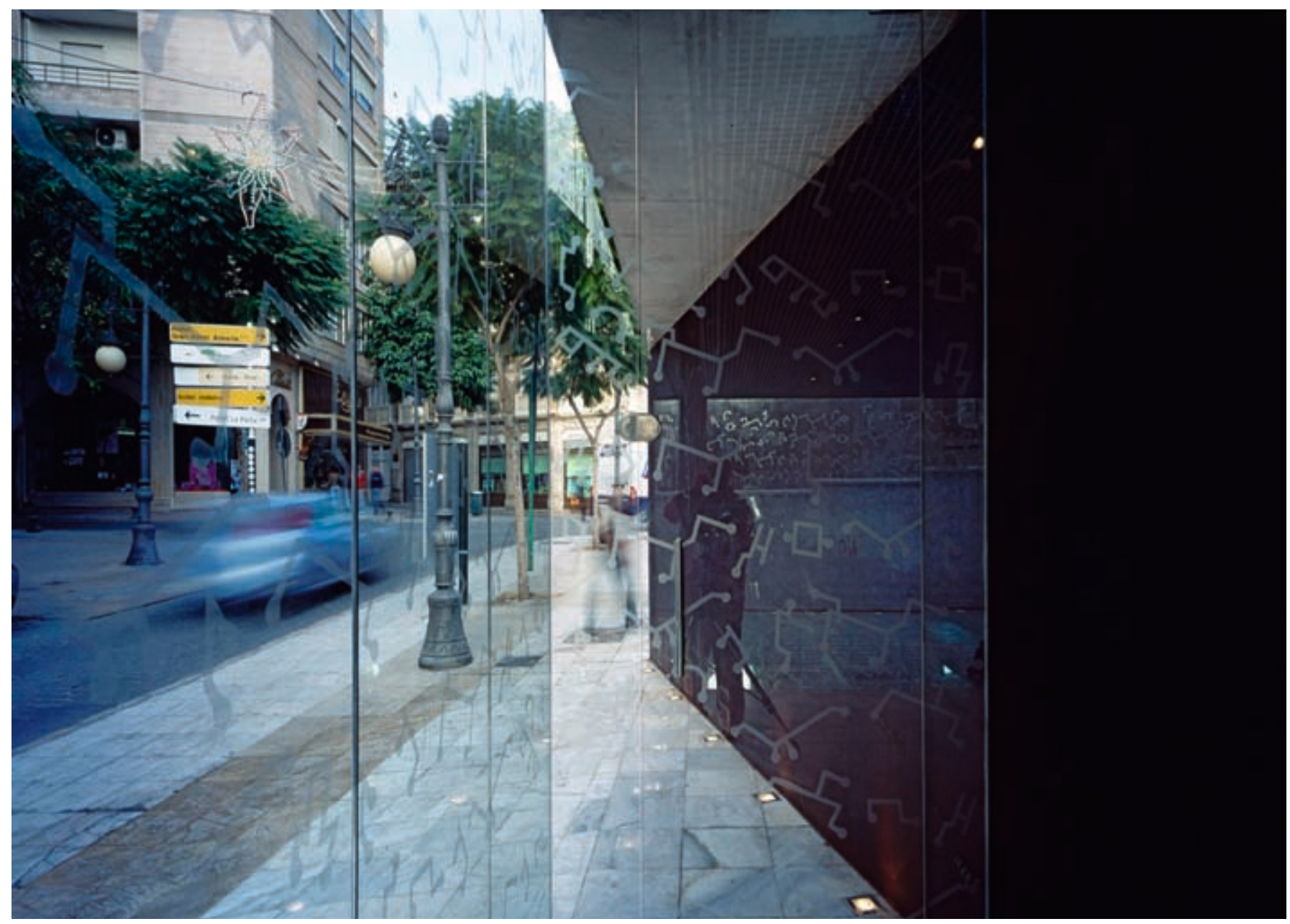

Vista desde el interior de la entrada del Pabellón de acceso. Foto: Jesús Granada

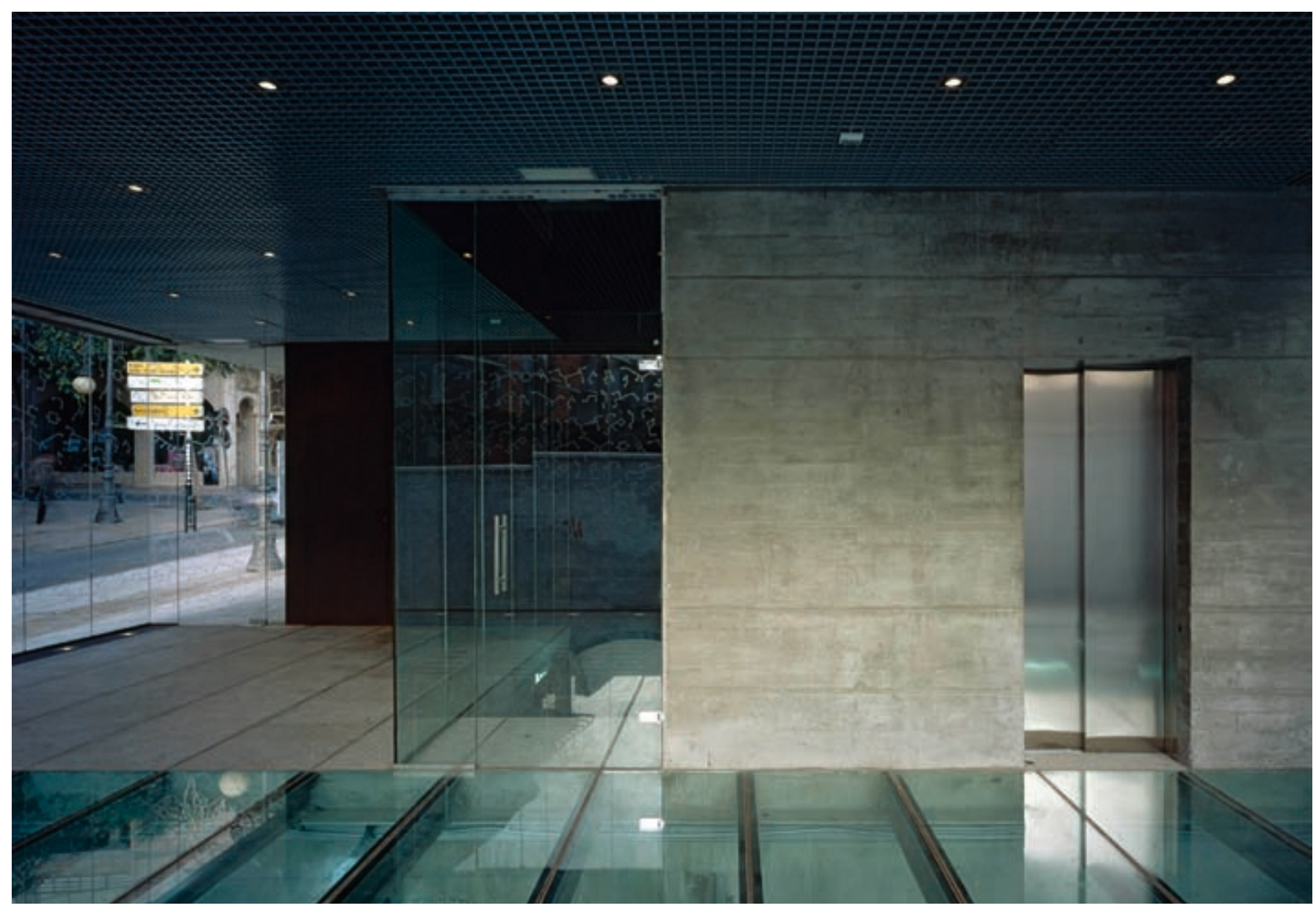

Interior del pabellón de acceso, con suelo de vidrio sobre restos arqueológicos. Foto: Jesús Granada 


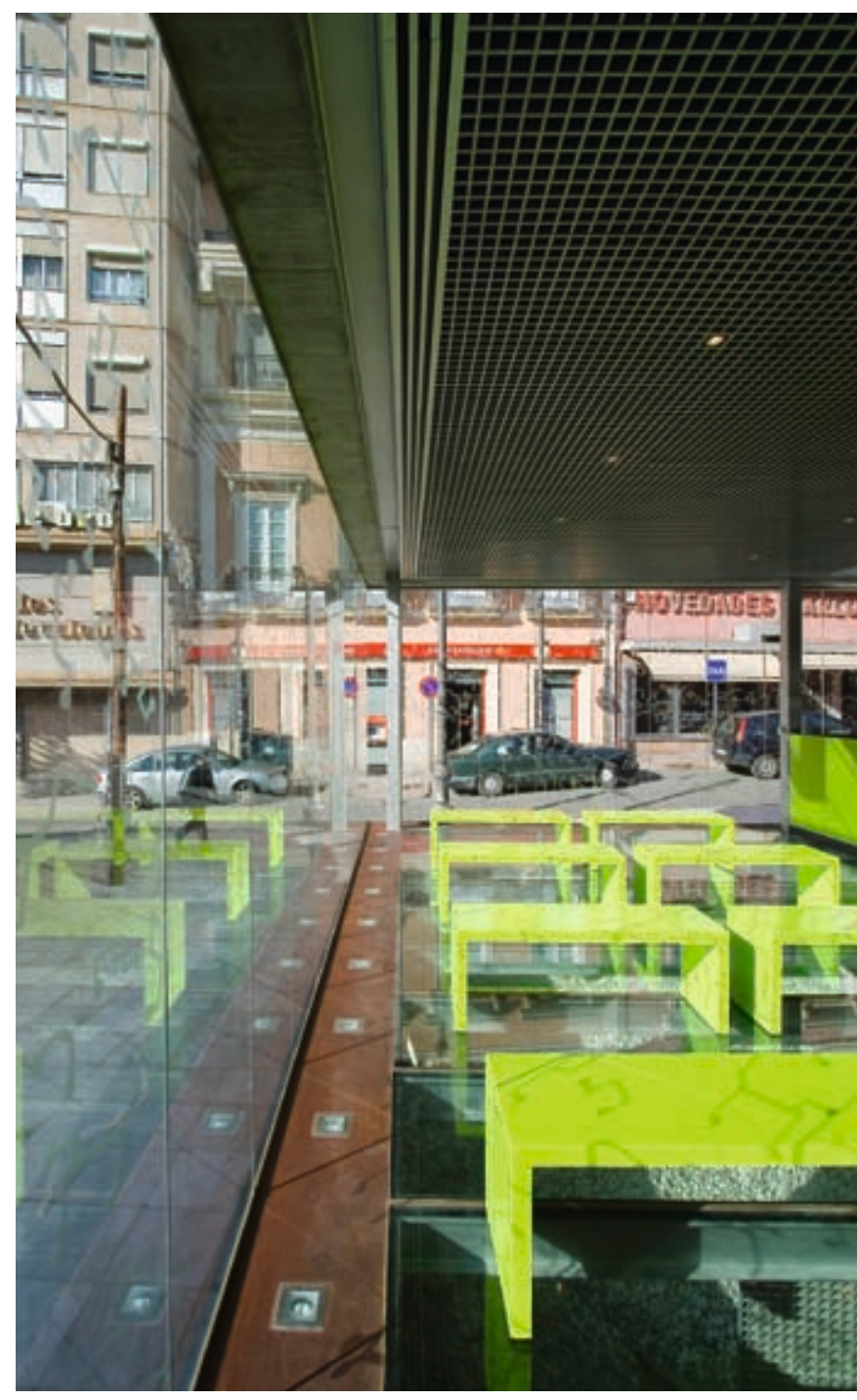

Interior del Pabellón de acceso, con mobiliario. Foto: Jesús Granada la contemporaneidad que, según nuestro criterio, debe presentar cualquier intervención actual.

Además, cada uno de los elementos se ha dotado de una escala y proporciones muy controladas y de una rigurosa elección de materiales. Todo ello dentro del respeto por lo existente, en aras de armonizar la solución propuesta con el contexto físico e histórico del lugar.

\section{El pabellón de acceso}

El pabellón de acceso aparece en la trama urbana como un elemento compacto de clara identificación formal, donde la concentración de elementos compositivos han dado lugar a un auténtico cofre, evocando así cuánto de valor tiene todo lo que podemos descubrir en su interior.

El proyecto del acceso se ha realizado desde la convicción de que la conciencia visual del entorno debía prevalecer sobre otras consideraciones. Se le dota, por tanto, de la mínima construcción: Una cubierta que flota sobre el espacio interior.

Se partía de un programa de necesidades muy estricto. Los usos previstos eran una sala para la acogida de visitantes, locales para el control de las instalaciones de las galerías, un aseo y un KioscoBar con acceso independiente.

La vinculación con lo existente se manifiesta mediante diferentes actuaciones, desde las propias trazas de la planta, que se apoyan en las de la obra original hasta en los acabados de los materiales, que hacen reiteradas referencias a los utilizados originalmente. Veamos cómo lo existente ha dejado su sello en la obra realizada.

Los restos de la antigua Puerta de Purchena se han integrado en el edificio, permitiendo su contemplación bajo un pavimento de vidrio, convirtiendo así al pabellón no sólo en la puerta de entrada a los refugios sino a una parte fundamental de la historia de nuestra ciudad: la Almeria islámica.

La parte del pabellón que cubre los restos arqueológicos se construye de la forma más leve posible. Para afianzar esta aserción, el volumen del pabellón no descansa sobre el terreno firme, lo que se puede observar al constatar la delgada línea de sombra que se produce en el contacto del pabellón con el suelo.

El edificio se organiza alrededor de la escalera que accede a los refugios, constituyéndose en el elemento a partir del cual se establece la conexión entre el pabellón y las galerias subterráneas, dotando a ambos de la debida continuidad como base para establecer la unidad del proyecto. El muro en el que se apoya la escalera, que con su grosor y su fuerza protegió a hombres y mujeres de su destrucción, aparece ahora como elemento generador del proyecto. A partir del muro, se dispone y desarrolla el programa dentro de un volumen compacto y transparente, paralelo al edificio que conforma la plaza y completamente abierto al centro histórico de 
la ciudad, como preludio del ámbito en el que los refugios y los restos de la Puerta de Purchena deben quedar integrados.

Por otra parte, el pabellón aparece desde la actual Puerta de Purchena como un elemento de poca altura, que no supera la planta baja del edificio más próximo y donde la caja de vidrio iluminada actúa como faro que reclama la atención del viandante. El pavimento exterior se introduce en el interior, en un gesto más de integración, conduciendo al visitante a lo que supondrá un apasionante viaje a la historia de la ciudad de Almería. Una vez dentro, el pabellón incorpora todo el espacio exterior mediante una visión panóptica de toda la plaza.

La horizontalidad de todos los elementos refuerza la idea de apego al terreno, en el ánimo de contribuir a su necesaria discreción. Esta horizontalidad sólo se ve perturbada por el espacio vertical que encierra la escalera y que se proyecta hasta la azotea, anclando el edificio al suelo y estableciendo la debida continuidad con las galerías subterráneas.

Esta continuidad entre refugios y pabellón se confía además al material y a la luz como los otros dos elementos que dan razón al proyecto. La luz marca la entrada a los refugios resbalando por el sólido muro de hormigón estucado que protegerá a todos los que se adentran, perdiéndose en el interior de la galería.

Esa luz, símbolo de esperanza, desciende desde lo más alto hasta la profundidad de la caverna, haciendo referencia a las bocas originales que siempre estaban abiertas y absorbian la luz exterior.

El estuco se utiliza en el proyecto original en la entrada al quirófano, tal y como se utilizaba en muchas de las entradas a las viviendas burguesas, contemporáneas a la construcción de los refugios y de las que permanecen algunos ejemplos como el vestíbulo de la vivienda situada en el Paseo de Almería, nº 4.

El pabellón debía aparecer también como un elemento sólido para así establecer la adecuada continuidad con la solidez de los refugios, pero a la vez debía ser transparente y ligero, de forma que se mitigara su presencia en la ciudad. Esta duplicidad se refleja en la condición y tratamiento de los materiales. La condición de sólido se confía a la textura del hormigón, al acero y a la condición reflectante del vidrio grabado. La transparencia y ligereza se transmite mediante las cualidades más inherentes del vidrio y las diferentes formas de introducir la luz cenital.

Además, se establecen una serie de vinculaciones al proyecto original y al contexto físico e histórico que retroalimentan las nuevas actuaciones: el acabado del hormigón hace referencia a las tablillas de madera utilizadas en el encofrado de las bóvedas de las galerías subterráneas; el grabado del acero corten de la entrada refleja los grafismos originales del proyecto de Langle, donde aparece la red de refugios proyectada en 1937 superpuesta sobre el plano actual de la ciudad; los grabados de los vidrios son una abstracción de los tramos de galerias existentes en la ciudad y que aparecian en los proyectos originales; los lucernarios abovedados hacen referencia a las propias bóvedas de las galerias. Así, las nuevas bóvedas están llenas de luz en contraposición a la oscuridad que reinaba muchas veces en los refugios. La solidez del hormigón siempre nos protege. Primero será la imposta que cubre el pabellón de acceso y luego, una vez dentro de los refugios, la propia bóveda de las galerías.

\section{La salida}

La salida de los refugios se resuelve mediante un tratamiento de parte del pavimento de la plaza Pablo Cazard, que acota y ofrece el soporte adecuado a los dos elementos principales: la escalera que se desarrolla paralela a la fachada del magnífico edificio del Teatro Cervantes y el ascensor que se posa paralelo a la Escuela de Artes. De esa forma, ambos elementos se insertan en la plaza, atendiendo a los dos edificios que la configuran, en un ejercicio de integración en el entorno. La fachada del Teatro actúa como telón de fondo de los dos elementos, realzando asi su importante presencia en la plaza, algo que hasta ahora no ocurria con la necesaria rotundidad al quedar desplazada respecto de los recorridos habituales que la atravesaban.

La salida mantiene la unidad del proyecto al establecerse la continuidad de soluciones y materiales con el resto de la actuación. Así los elementos de vidrio que alojan independientemente el ascensor y la escalera presentan los mismos grabados que en el pabellón de acceso, manteniendo así la transparencia necesaria para la percepción del entorno, convirtiéndose en una alegoria de los propios refugios a través de los cuales se alcanza la luz del día, la luz de la vida.

La escalera de salida se enfrenta intencionadamente a la puerta principal de la Escuela de Artes, permitiendo así la visión directa del magnífico patio del antiguo convento de los dominicos construido en el S. XVIII, en el convencimiento de que esa conexión visual contribuye al entendimiento de los refugios como un elemento más del patrimonio histórico de la ciudad de Almería.

En definitiva, toda la actuación está plagada de guiños al lugar en un intento de vincular la actuación a su contexto físico y cultural, dentro del máximo respeto por lo existente conservando el carácter original de la obra y del más estricto rigor en el tratamiento de los nuevos elementos, valores que hemos intentado mantener desde el inicio en todas nuestras actuaciones.

\section{Nota}

Este artículo se publicó por primera vez en el libro Los refugios de Almería, un espacio para la vida, editado por el Excmo. Ayuntamiento de Almería en el año 2007. 


\section{LOS REFUGIOS DE ALMERÍA. DE LA OSCURIDAD A LA PENUMBRA}

\section{Manuel Ramos Lizana}

Conservador de museo

Esta breve reseña sobre los refugios de la Guerra Civil en Almería sólo puede comenzar con una felicitación por la iniciativa del Ayuntamiento de Almería al poner en valor un patrimonio de cuya existencia tan sólo tenían noticia verbal la mayoria de los almerienses. Las personas mayores habian relatado siempre cómo durante algunos periodos de tiempo era posible descender a las galerias construidas por el Gobierno de la República simplemente como un juego. Los aún más mayores -y por tanto mucho más escasos- guardaban la memoria directa de haber sido infortunados usuarios de los refugios. Pero, no obstante, esa nutrida red de galerias estaba ahi, discurriendo paralela y subterráneamente a la vida cotidiana de los almerienses. Su apertura pública es, por tanto, una saludable noticia.

Lo que ahora ve la luz es una pequeña parte de toda esa trama de galerias puesta a disposición de los ciudadanos en forma de visita pública que implica, obviamente, una preselección del recorrido. Una operación multidisciplinar en la que han participado arqueólogos, arquitectos, documentalistas y museógrafos se nos presenta, en primer lugar, como intervención arquitectónica. Fue necesario arbitrar un pabellón de entrada en Puerta Purchena, el epicentro simbólico de la ciudad; y una salida para los visitantes junto a la Escuela de Artes, aún en pleno casco histórico. Dicha actuación fue resuelta con solvencia y calidad, arbitrando unos elementos no sólo correctos en cuanto a volumetria, elección de materiales o integración urbana. También el acabado y el diseño son de una factura delicada y cualificada.

Como buena intervención pluridisciplinar, el proyecto incluye la puesta en valor de un lienzo de muralla inmediato a la impropiamente conocida como Puerta de Purchena (en realidad, Puerta de Pechina), uno de los elementos clave en la traza urbana de la Almería andalusi. Este lienzo puede observarse bajo el piso acristalado del pabellón de acceso.

En cuanto a lo que solemos denominar "Museografia", la visita pública se ha organizado en la forma que explicamos a continuación. La duración del recorrido a pie es de aproximadamente una hora y media y se realiza en grupos de unas quince personas, en horario de mañana salvo los viernes (en que también hay apertura vespertina). Siempre, mediante cita previa. En primer lugar, y en el mismo acceso, los grupos tienen la po- sibilidad de visionar una suerte de documental de unos 8 o 9 minutos de duración construida básicamente sobre testimonios directos de supervivientes locales y su experiencia directa en relación con los refugios. Se trata, sin duda, de una pincelada que puede servir eficazmente como reclamo de la atención y como pellizco emotivo que capte a los visitantes por su lado más sentimental. Aunque hemos de decir que se echan en falta una mayor contextualización tanto sobre la Guerra Civil como sobre las peculiaridades locales del conflicto. Tan sólo un par de fotografías que, a menudo quedan en un simple fondo, nos contextualizan abiertamente el conflicto y sus actuantes. Son, en fin, referencias más visuales que verbales que no todo el mundo está capacitado para interpretar, especialmente los más jóvenes 0 los turistas extranjeros.

El recorrido consta de unas quince paradas de corta duración con los comentarios del monitorguía a los visitantes, que tienen la oportunidad de sentarse en los mismos bancos que ocupó la población civil durante los bombardeos. A éstos se añade el visionado de paneles o bien de proyecciones sobre una pantalla que el monitor hace girar hasta quedar transversal a la galería. En estas proyecciones hay un hilo conductor, la historia de un abuelo que ha descendido a los refugios con su nieto tras escuchar las sirenas. El abuelo va consolando al niño prometiéndole un regalo que, al final de la visita resulta ser la propia vida puesta a salvo una vez más y la esperanza de un futuro mejor. El hecho que aqui se obvia (casi diriamos, se escamotea) es que el futuro no iba a ser otro que varias décadas de dictadura.

En este punto creemos que el enganche emotivo ha ido -tal vez- demasiado lejos y en un sentido no demasiado afortunado. $Y$ volvemos a sentir la necesidad de una mayor aproximación al fenómeno sobre el que se quiere transmitir algo. De hecho, llega a tenerse la sensación de que -en un afán por no herir sensibilidades- se han obviado todo tipo de cuestiones. Hasta el punto de que uno puede llegar a tener la impresión de que las bombas caian del cielo como hubiera podido hacerlo el pedrisco, como una catástrofe natural más. Todos sabemos que no fue exactamente asi y también que hubo episodios especialmente cruentos en el trascurso de la Guerra Civil en Almería sobre los que no se nos dice nada -o casi nada-. Asi por ejemplo, la masacre de las columnas de civiles que huyeron de Málaga hasta Al- mería por la antigua carretera de la costa, donde fueron bárbaramente ametrallados y bombardeados por diversos medios. También se echa de menos un comentario amplio sobre la actuación de la Legión Cóndor, que tan sólo es lateralmente mencionada por el monitor en el trascurso de la visita. Lo que ésta hizo en España fue ensayar formas de masacrar a la población civil en los conflictos bélicos que hasta entonces nadie se habia atrevido a llevar a cabo y que hoy por hoy continúan siendo habituales. Y Almería, no hay que olvidarlo, fue uno de esos ensayos.

Finalmente, tenemos que hacer un pequeño comentario sobre la conservación de los refugios. Éstos estuvieron durante décadas completamente cerrados y por tanto, mantuvieron una estanqueidad que debió favorecer su conservación. El sistema de ventilación originario ya había quedado en desuso décadas antes de la actuación que aqui estamos comentando. La nueva intervención arquitectónica supuso la introducción de un sistema de ventilación artificial que tan sólo funciona en las horas de apertura pública. Esto ha introducido -sin duda- ciertos cambios diarios de las condiciones termohigrométricas que, muy probablemente, han debido tener un impacto sobre los refugios. Asi, el autor de esta reseña ha podido ver cómo en cuatro meses de diferencia, que son los que median entre las dos visitas realizadas, las eflorescencias salinas (extraordinariamente visibles) han causado serios daños en paredes y escalones provocando considerables desprendimientos. Es este un extremo, por tanto, que bien requeriría una revisión, una vez contrastados los resultados de la intervención. 


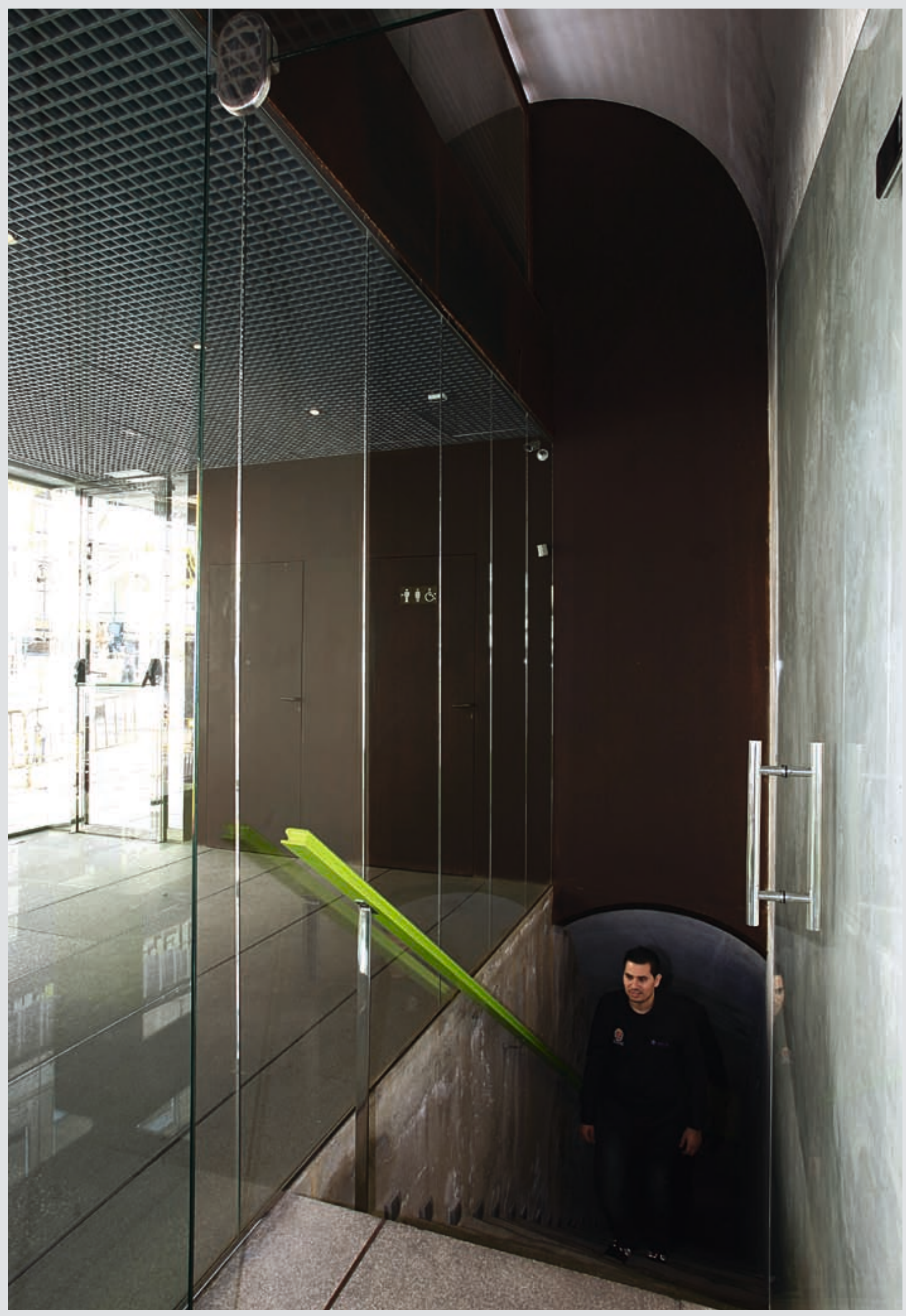

Pabellón de entrada. Foto: Miguel Ángel Blanco de la Rubia 